\title{
DOSSIER
}

\section{LA LIBERTAD DE IMPRENTA \\ EN EL SIGLO XIX: \\ VAIVENES Y TENSIONES \\ DE SU REGULACIÓN. PRESENTACIÓN}

T as libertades de expresión y de imprenta están estrechamente unidas y forman parte de un binomio indisociable en el que se entrelazan y complementan. ${ }^{1}$ Constituyen un aspecto fundamental de la vida política del país desde que éste se formó, tras independizarse de España -y en estricto sentido le antecede-, que se ha desarrollado en el tiempo llegando hasta nuestros días. Gracias a ellas el debate público ha sido posible y, a su vez, son parte integral de ese mismo debate, enfocado en su defensa o su impugnación, según el caso. Ambas libertades han sido usadas políticamente por diversos actores, por las autoridades y representantes de los tres poderes -Ejecutivo, Legislativo y Judicial-, por los miembros de la oposición al gobierno y por los críticos del sistema. Así, políticos, intelectuales, artistas, abogados, impresores y ciudadanos en su conjunto se han posicionado a favor o en contra de su existencia y de su reglamentación, amén de haberlas ejercido para sus fines e intereses, o haberse visto

1 Agradezco las lecturas y comentarios a este texto de Elisa Cárdenas, Laurence Coudart, Florencia Gutiérrez y Matilde Souto y de los integrantes del Seminario de Historia Política del Instituto Mora. 
constreñidos por sus términos. El debate sobre el tema es vasto y de vigencia renovada.

Otro binomio indisociable es el de la libertad de imprenta y su regulación, esto es, los límites que se le imponen, los cuales incluyen la censura -previa o posterior-, controles formales e informales, reglamentaciones, restricciones, prohibiciones y aun la represión -legal o extralegal- con diversos grados de violencia. Las legislaciones, así como las diversas estrategias de control sobre la imprenta, en general, y la prensa, en particular, constituyen un eje vertebral y revelador de los proyectos e intereses de partidos y grupos políticos, cualquiera que sea su filiación o ideología. Especialmente de aquellos que actúan como gobierno, pero también de aquellos que en el espacio público se sitúan como su contraparte, y de la sociedad política toda, pues el cruce de esos proyectos e intereses en su conjunto, sus tensiones y equilibrios, son los que dan cuerpo al Estado-nación, definen las identidades colectivas derivadas del mismo, conforman y renuevan lenguajes políticos, articulan procesos democratizadores o modernizadores. En fin, que regulación y control de la imprenta son herramientas privilegiadas para actuar en política. Las discusiones sobre el tema se proyectan en el tiempo marcando periodos de gran agitación política en la esfera pública.

Los usos políticos de la libertad de imprenta son variados e impactan significativamente en el conjunto de las sociedades; su regulación misma los entraña. ${ }^{2}$ Así encontramos, por un lado, a quienes demandaban $-\mathrm{y}$ demandan- su respeto y observancia

${ }^{2}$ En los últimos años de vida colonial, esto es, a partir de la emisión de la Constitución de Cádiz en 1812, se usó el término libertad política de imprenta para diferenciarla de la libertad religiosa. Esta diferencia se mantuvo en la primera Constitución mexicana, la de 1824, que garantizó la "libertad política de imprenta”, y continuó en la centralista Ley Constitucional de 1836. El cambio se operó en 1857, cuando la nueva Constitución garantizó la "libertad de escribir y publicar escritos sobre cualquier materia”. Fernando GómEZ DE Lara, Manuel González Oropeza, David M. Vega Vera y Javier Zenteno Barrios, Estudios sobre la libertad de prensa en México, México, Universidad 
o exigían -exigen- que la libertad sea irrestricta, acusando al gobierno, y a quienes están a favor de su acotamiento, de poner trabas e imponer límites, someter y reprimir a quienes no están de acuerdo con el sistema imperante. Por el otro, a quienes -principalmente las autoridades, aunque no exclusivamente, porque también los propios periodistas, intelectuales y políticos de todo orden- han buscado -y buscan- acotar los márgenes de esa libertad aduciendo la necesidad de proteger el interés común, el orden, la legalidad, la estabilidad institucional, la paz colectiva, la autoridad del Estado. En términos del desarrollo de la prensa y de la conformación y consolidación de los estados nacionales latinoamericanos, el siglo XIX se caracterizó por ser el de las tensiones entre el reconocimiento de la libertad de imprenta y expresión, entendida como base fundamental de los sistemas republicanos y del liberalismo, y su identificación como un factor que atentaba contra los poderes establecidos, trastocando el orden, como un factor de disolución. Las consideraciones respecto a la libertad de prensa oscilaban entre hacerla el estandarte del progreso o mostrarla como un peligro para la estabilidad y la paz nacional.

En este dossier, por medio de cuatro estudios -unos focalizados, otros de más amplio espectro-, nos ocupamos de la libertad de imprenta -y de la de expresión, que va estrechamente asociada a ésta-, en la centuria decimonónica, tratando de acercarnos a aspectos poco estudiados, como son el de su legislación y el de las tensiones entre libertad y orden que trajo aparejado y que definió gran parte de los debates sobre su regulación. En sus colaboraciones, Abraham Chimal, Laurence Coudart, Fausta Gantús y Víctor Villavicencio se adentran en momentos específicos o periodos más o menos amplios, según el caso, para mostrar cómo se fueron definiendo y aplicando las leyes en la

Nacional Autónoma de México, Corte Constitucional de Guatemala, 1997, pp. 17-34. 
materia en determinadas coyunturas, mostrando también las diferencias entre la letra de la ley y la práctica.

Cabe precisar que lo poco que sabemos sobre legislación de imprenta se refiere a las disposiciones federales y que prácticamente desconocemos lo sucedido en los estados. La Constitución de 1824 dejó en las entidades federativas la responsabilidad de proteger esa libertad, y cada una la garantizó de forma particular. ${ }^{3}$ La de 1857, aunque no lo hizo de manera expresa en la materia de libertad de imprenta, reconoció la capacidad de cada Estado para emitir leyes para su gobierno interior.

En general, los trabajos producidos sobre la libertad de imprenta, ya aludan a ella de manera referencial, ya centren su atención en el tema mismo, asumen que su regulación es un asunto de carácter federal, y prácticamente ninguno se detiene en las posibles disposiciones de los estados en la materia. Y ello es así, no por estar en el entendido de que las leyes locales no pueden contravenir las de carácter federal, sino porque lo cierto es que ni siquiera nos hemos dado a la tarea de preguntarnos por las realidades estatales en lo que toca a la legislación de prensa. Éste es un tema que la historiografía mexicana no ha desarrollado porque quizá aún sabemos tan poco sobre el marco nacional que la exploración de los particulares se ha quedado pendiente. Lo cierto es que los estudios de caso en la materia están aún en ciernes.

$$
* * *
$$

Durante el siglo xx, el marco constitucional que regula a la imprenta en México (1917-2017) se mantuvo sin cambios. En 1917 se promulgó una nueva Constitución y se emitió una Ley de Imprenta -también conocida como Ley sobre Delitos de

\footnotetext{
${ }^{3}$ Reynaldo Sordo Cedeño, "La libertad de prensa en la construcción del estado liberal laico, 1810-1857”, en Margarita Moreno-BonetT y Rosa María Álvarez Lara, El Estado laico y los derechos humanos en México: 1810-2010, México, Universidad Nacional Autónoma de México, 2012, t. I, p. 137.
} 
Imprenta-, misma que, aunque reformada en varias ocasiones, ${ }^{4}$ continúa vigente hasta la actualidad, y reglamenta a la imprenta y la libertad de expresión. ${ }^{5}$

En la Constitución los artículos que garantizan lo relativo a la libertad de expresión y de imprenta continúan siendo el $6^{\circ}$ y el $7^{\circ}$, respectivamente, igual que en la de 1857. En la carta fundamental promulgada en 1824 se señaló en el artículo 50, fracción III, como facultad "exclusiva" del Congreso general "Proteger y arreglar la libertad política de imprenta, de modo que jamás se pueda suspender su ejercicio, y mucho menos abolirse en ninguno de los Estados ni territorios de la federación”. En tanto en el artículo 161, fracción IV, se estipuló como "obligación" de los estados: "Proteger a sus habitantes en el uso de la libertad que tienen de escribir, imprimir y publicar sus ideas políticas, sin necesidad de licencia, revisión o aprobación anterior a la publicación; cuidando siempre de que se observen las leyes generales de la materia". ${ }^{6}$ En lo que toca a la libertad de expresión, el artículo $6^{\circ}$ estipuló en 1917 que: "La manifestación de las ideas no será objeto de ninguna inquisición judicial o administrativa, sino en el caso de que ataque a la moral, los derechos de terceros, provoque algún delito, o perturbe el orden público". Con lo cual se mantuvo prácticamente idéntico al de 1857 , salvo por el tiempo verbal que pasó de "no puede ser" a "no será", y porque se suprimió el término "crimen" que acompañaba al de delito. Este artículo, sin embargo, sufrió una

${ }^{4}$ La última reforma es de 4 de noviembre de 2015, que derogó el artículo 27 de la Ley de 1917.

${ }^{5}$ Un par de estudios, aunque no son los únicos, centrados en leyes de imprenta en el siglo xix, son: Florence Toussaint Alcaraz, Periodismo, siglo diez y nueve, México, Universidad Nacional Autónoma de México, 2006 y Carolina Martínez Quintero, "Ley Lares: 'Hay que acallar a la prensa anárquica, poco inteligente y hostil' (1853-1855)”, tesis de licenciatura, México, Universidad Nacional Autónoma de México, 2013.

${ }^{6}$ Constitución Política de la República Mexicana, de 1857. Constitución Federal de los Estados Unidos Mexicanos, de 1824. 
reforma sesenta años después, en 1977, cuando se adicionó en su parte final: "el derecho a la información será garantizado por el Estado"; sin embargo, sería hasta 2002 cuando esta reforma se tradujera en una ley que la regulara.

En julio de 2007 al artículo se le incorporaron siete fracciones relacionadas con el derecho de acceso a la información. Finalmente, en noviembre del mismo año el artículo se reformó de nuevo para incluir lo relativo al derecho de réplica. ${ }^{7}$ De esta forma, el artículo $6^{\circ}$ garantiza en la actualidad la libre manifestación de las ideas pero también otros dos aspectos: el derecho de réplica, relacionado con los efectos de la difusión y los medios de comunicación mediante los cuales se dan a conocer opiniones; y con el acceso a la información, que atañe principalmente a las políticas gubernamentales respecto al manejo de la documentación oficial.

En el caso del artículo $7^{\circ}$ en 1917 se asentó:

Es inviolable la libertad de escribir y publicar escritos sobre cualquier materia. Ninguna ley ni autoridad pueden establecer la previa censura, ni exigir fianza a las autoridades o impresores, ni coartar la libertad de imprenta, que no tiene más límites que el respeto a la vida privada, a la moral y a la paz pública. En ningún caso podrá secuestrarse la imprenta como instrumento del delito.

Las leyes orgánicas dictarán cuantas disposiciones sean necesarias para evitar que so pretexto de las denuncias por delito de prensa, sean encarcelados los expendedores, 'papeleros', operarios y demás empleados del establecimiento donde haya salido el escrito

\footnotetext{
7 "La manifestación de las ideas no será objeto de ninguna inquisición judicial o administrativa, sino en el caso de que ataque a la moral, los derechos de tercero, provoque algún delito, o perturbe el orden público; el derecho de réplica será ejercido en los términos dispuestos por la ley. El derecho a la información será garantizado por el Estado". Constitución Política de los Estados Unidos Mexicanos, de 1917.
} 
denunciado, a menos que se demuestre previamente la responsabilidad de aquellos. ${ }^{8}$

La redacción del artículo se ha mantenido sin reformas desde entonces. ${ }^{9}$ Cabe señalar que el contenido del artículo en su primera parte es exactamente igual al de 1857 , aunque se le adicionó la prohibición de incautar las imprentas. El cambio importante está en la parte final del artículo, que en 1857 establecía: "Los delitos de imprenta serán juzgados por un jurado que califique el hecho, y por otro que aplique la ley y designe la pena"; y que había sido reformado en 1883 quedando asentado que: "Los delitos que se cometan por medio de la imprenta serán juzgados por los tribunales competentes de la Federación o por los de los Estados, los del Distrito Federal y territorio de la Baja California, conforme a su legislación penal". ${ }^{10}$ En tanto, en 1917 se precisó que se emitiría una ley orgánica para regular el ejercicio de la imprenta. Éste no es un cambio menor, pues la reforma de 1883 dejaba sometido al imperio de los tribunales de orden común y sujetos a los códigos penales vigentes -en la Federación y los estados- los delitos cometidos por medio de la imprenta. ${ }^{11}$ Con la nueva Constitución se garantizaba la existencia de una ley específica para arbitrarlos y juzgarlos, misma que fue emitida el 9 de abril de ese año.

${ }^{8}$ Constitución Política de los Estados Unidos Mexicanos, de 1917.

${ }^{9}$ Consideramos las reformas publicadas al 17 de agosto de 2011, que son las más recientes que pudimos ubicar.

10 Constitución Política de la República Mexicana, de 1857. Para seguir las propuestas de modificación y la reforma del artículo $7^{\circ}$ a partir de su emisión en 1857 véase el anexo 3: "Artículo $7^{\circ}$ constitucional: propuestas, aprobación y reforma”, en el artículo de Gantús en este dossier.

${ }^{11}$ En particular los artículos 49 fracc. III, 644, 648, 656, 657, 658, 660, 785, 786, 839, 909, 910, 1110 del Código Penal para el Distrito Federal y Territorio de la Baja California sobre delitos del fuero común, y para toda la República sobre delitos contra la Federación, 1872. 
Es significativo que tras un siglo como el xx, marcado por el desarrollo y expansión de los medios de información y comunicación, desde el cine y la radio hasta la internet, pasando por la televisión, la Constitución mexicana vigente sólo garantiza lo relativo al derecho de imprimir y de publicar escritos, sin incluir aún las otras formas -y los demás medios- de expresión y comunicación. Aunque sabemos que se han dictado algunas leyes en las diversas materias, tales como la Ley Federal de Radio y Televisión, que se promulgó en 1960, y fue reformada en 2006 y en 2012 y abrogada en 2014; ${ }^{12}$ la Ley Federal de Telecomunicaciones y Radiodifusión, emitida en $2014 ;{ }^{13}$ y tuvimos noticia del intento de ley promovida para prevenir y sancionar los delitos informáticos en 2015; y hay que señalar que la Ley de Libertad de Imprenta del 9 de abril de 1917 contempló lo relativo a las representaciones teatrales, exhibiciones de cinematógrafo y audiciones de fonógrafo; lo que llama la atención es la persistencia de la redacción original del artículo en el texto constitucional. ${ }^{14}$

Aunque no haremos aquí un análisis de la ley de imprenta vigente en la actualidad, si hay un par de cuestiones sobre las que queremos detenernos -aunque en realidad gran parte de la ley requeriría una crítica puntual, ello rebasa las pretensiones de este dossier $-{ }^{15}$ por su estrecha vinculación con temas que fueron

12 Ley Federal de Radio y Televisión, 1960, reformada en 2007. DE: http:// www.sct.gob.mx/fileadmin/_migrated/content_uploads/Ley_Federal_de_ Radio_y_Television.pdf

${ }^{13}$ Ley Federal de Telecomunicaciones y Radiodifusión, 2014. De: http:// www5.diputados.gob.mx/index.php/camara/Comision-de-Radio-y-Television/Ley-Federal-de-Telecomunicaciones-y-Radiodifusion.

${ }^{14}$ En 1913 se emitió un reglamento de cinematógrafos y sus adiciones, en tanto en 1949 se promulgó la Ley de la Industria Cinematográfica. Sobre el tema véase Adriana Berrueco García, Nuevo régimen jurídico del cine mexicano, México, Universidad Nacional Autónoma de México, 2009, pp. 1 a 43.

15 Sobre el tema de las libertades de expresión y de imprenta en la actualidad, a partir del análisis de la Constitución de 1917, véase Juan Ferreiro GalgueRA, "Libertad de imprenta en México: hacia una ley federal de comunicación 
centrales en las discusiones del siglo xix. Como puede observarse, perduran términos, usados en ambos artículos constitucionales, como "moral”, "vida privada" y "orden público" o "paz pública", acompañados de "respeto", "ataques", "provocar" o "perturbar", que son los límites impuestos a la libertad de expresión y de imprenta, pero que resultan conceptos problemáticos por la ambigüedad que entrañan. Por ello, sin duda, a través de varios de los artículos de la Ley de Imprenta de 1917 se buscó definir lo que constituye un "ataque" a los mismos. ${ }^{16}$ Sería largo entrar a discutir este tema aquí, pero lo que queremos es señalar un asunto importante que atravesó gran parte de las prácticas y de las discusiones en torno a la libertad de expresión y al ejercicio de la libertad de imprenta a lo largo del siglo xix. Como muestra, baste decir que los "ataques a la vida privada", consignados y penados en la ley de 1917, se derogaron recientemente, en enero de 2012. ${ }^{17}$

En efecto, cuestiones como ¿qué se entiende por un ataque a la moral? resultan difíciles de definir. La moral y la vida privada, aunque no se explicitara, estaban estrechamente asociadas a la idea del honor, mismo que tuvo un lugar relevante en la vida pública y el desempeño político de los actores de época, en la construcción de la "autoridad política" y en el desarrollo de la nación. ${ }^{18}$ También, como lo apunta Laurence Coudart, la reglamentación que defendía la moral y las buenas costumbres

social", en Anuario da Facultade de Dereito da Universidade da Coruña, 5 (2001), pp. 289-314.

${ }_{16}$ Artículos $1^{\circ}, 2^{\circ}$ y $3^{\circ}$ de la Ley de imprenta, o Ley sobre delitos de imprenta, de 1917.

17 Decreto por el que se derogan los artículos $1^{\circ}$ y 31 de la Ley sobre Delitos de Imprenta, 11 de enero de 2012.

18 Pablo Piccato, La tirania de la opinión. El honor en la construcción de la esfera pública en México, México, Instituto Mora, El Colegio de Michoacán, 2015, en particular, pp. 21-155. Fausta GanTús, Caricatura y poder político. Crítica, censura y represión en la ciudad de México, 1876-1888, México, El Colegio de México, Instituto Mora, 2009, pp. 290-312. 
tenía en su base la búsqueda de la cohesión social y nacional. Y ¿ cómo dibujar con nitidez lo que constituía un ataque, una provocación o una franca perturbación al orden o la paz públicos? Abierta a la interpretación, la decisión de calificar un escrito en tales términos se dejaba al arbitrio de los impartidores de justicia, que podían hacer casi de cualquier crítica contra las autoridades un llamamiento a la rebelión. ${ }^{19}$ Entonces, ¿ cómo determinar y cómo proteger el honor y la vida privada?, ¿y cómo resguardar la seguridad de la nación? Esto es, ¿era necesario regular la prensa? ¿ Cómo hacerlo? ¿En qué términos podían garantizarse las libertades de expresión y de imprenta al tiempo que se preservaran los derechos de terceros y la autoridad gubernamental? Este debate marca toda la centuria decimonónica. $\mathrm{Al}$ respecto diversos intelectuales y políticos a lo largo del siglo expresaron sus opiniones, fijaron sus posiciones y sostuvieron intensos debates, ya desde el momento mismo de la transición del régimen colonial a la vida independiente, como lo muestra Abraham Chimal en su colaboración con la disputa sostenida entre José María Cos y José Mariano Beristain..$^{20}$

Esto nos lleva, obligadamente, al tema central del artículo $7^{\circ}$, a la ley de imprenta y al tema de este dossier: la libertad de imprenta, su regulación y aplicación. Asunto complejísimo sobre el cual las discusiones se han multiplicado a lo largo de los dos siglos de existencia de nuestro país. ¿Existe la libertad irrestricta, así, en general? Y, en lo particular, ¿es posible la existencia de la libertad de imprenta sin ningún tipo de censura? ¿Y lo es sin ningún tipo de restricción o regulación? En este contexto, es posible afirmar que la censura limita, pero ¿limitar es censurar? Mucha confusión hay sobre este punto.

19 Véase, al respecto, el caso de la deuda inglesa y la creación de la figura de la “psicología” desarrollados por GANTús, Caricatura, pp. 312-383.

20 Para los primeros años del siglo xix véase Susana Ma. Delgado Carranco, Libertad de imprenta, política y educación: su planteamiento y discusión en el Diario de México, 1810-1817, México, Instituto Mora, 2006. 
Esfuerzos por entender, analizar y explicar la libertad de imprenta, así como reflexiones y argumentaciones en el mismo sentido se han desarrollado desde la historia y el derecho, especialmente. Las discusiones, como anotábamos antes, han estado y continúan estando vigentes en la actualidad cuando tratamos de entender la práctica, el ejercicio, la regulación y los debates de la libertad de imprenta decimonónica. Como apunta Laurence Coudart en su colaboración, "la implementación de dicha libertad constituye un problema complejo que no se puede tratar de manera maniquea o esencialista”.

Para adentrarnos en este punto debemos decir algo, muy brevemente, sobre la censura de la imprenta que, como es sabido, ha existido y existe de muy diversas formas. ${ }^{21}$ Lo primero que queremos hacer es puntualizar una diferencia, que consideramos fundamental, relacionada con el uso del término tanto por parte de los actores de la época como por parte de quienes estudian el fenómeno, que no hemos visto explicitado en ningún trabajo sobre el tema. Se trata de diferenciar el uso retórico del concepto censura, de su uso legal y judicial, y aun del práctico.

En estricto sentido, la censura sólo es posible cuando una obra es sometida a dictamen o evaluación, ya sea de manera previa a su publicación, o bien una vez publicada, pues requiere que "se forme juicio de alguna obra o cosa". ${ }^{22}$ También censurar es "corregir o reprobar" a algo o a alguien. En tal sentido,

${ }^{21}$ Sobre el tema de la censura y el papel de los censores véase el trabajo de Robert Darnton, Censores trabajando. De cómo los Estados dieron forma a la literatura, México, Fondo de Cultura Económica, 2014.

${ }^{22}$ Las definiciones de los diccionarios, durante el siglo xIx y hasta la actualidad, así lo establecen. Existen diversos diccionarios publicados a lo largo de los dos siglos que dan cuenta de ello. Sería largo enumerarlos aquí, y anotaremos sólo algunos: M. NúÑEZ DE TABOADA, Diccionario de la lengua castellana, 2 vols., París, Seguin, 1825; Elías Zerolo, Diccionario enciclopédico de la lengua castellana, 2 vols., París, Garnier hermanos, 1895; Manuel RodríGuezNaVAS y Carrasco, Diccionario general y técnico hispano-americano, Madrid, Cultura Hispanoamericana, 1918. 
podemos debatir sobre la pertinencia o no, las razones justificadas o no, los intereses evidentes u ocultos, del gobierno y otras instituciones y actores -individuos, corporaciones, particularmente las religiosas, etc.-, para censurar impresos, pero hay que evitar achacarle o confundir la censura con los diversos límites impuestos a la libertad de imprenta, así como llegar al exceso de considerarla la forma privilegiada para actuar contra la prensa. Esto es, censurar no es sinónimo de regular, prohibir, reprimir..., aunque en el uso retórico se equiparen. Como señala Darnton, "identificar la censura con restricciones de todo tipo significa trivializarla". ${ }^{23}$ Aunque evidentemente la censura limite, la idea de su existencia es que debe hacerlo con base en un juicio razonado, fundamentado, que justifique suficientemente los motivos de la misma. Cabe señalar que aun durante la etapa colonial, la censura, a pesar de ser previa, no era necesariamente, o al menos no siempre, concebida como una acción represora sino como un examen al que debían someterse las obras a fin de garantizar su contenido.

En principio, la censura en el México independiente no funcionó como estrategia para evitar la publicación de un escrito, pues a partir de la promulgación de la Constitución de 1824 la garantía de publicar sin previa censura quedó establecida. ${ }^{24}$ En realidad ya en 1810, en el decreto IX, de 10 de noviembre, emitido por las Cortes de Cádiz, se consignó la libertad de "escribir, imprimir y publicar [...] sin necesidad de licencia, revisión o aprobación alguna anterior”, para las obras de carácter político, pero manteniéndose la previa censura para las que se ocuparan de materia religiosa. La Constitución de Apatzingán, de 1914, en su artículo 40 consignó para los ciudadanos "la libertad de hablar, de discurrir y de manifestar sus opiniones por medio de la imprenta", autorizando la prohibición de los mismos sólo

23 Darnton, Censores, p. 12.

${ }^{24}$ Artículo 50, fracc. III, y artículo 161, fracc. IV. Constitución de 1824. 
en casos concretos en que se atacara el dogma, se perturbara la tranquilidad pública o se ofendiera el honor de un tercero, pero no aclaró si esa prohibición sería previa a la publicación. En la línea trazada por Cádiz y Apatzingán, en 1822, en el Reglamento Provisional del Imperio Mexicano se decretó la supresión de la previa censura para todas las obras excepto para aquellas que tocaran cuestiones eclesiásticas y de religión, así como las relacionadas con la monarquía, la figura del emperador y los principios fundamentales de independencia y unión.

A pesar de los cambios de régimen de gobierno que experimentó el país durante la primera mitad del siglo, la disposición sobre prohibir la censura previa se mantuvo en los textos fundamentales del país, tanto en las Siete Leyes de 1836 como en las Bases Orgánicas de 1843 y en el Acta de Reformas de 1847. Cabe señalar que ni siquiera la restrictiva Ley Lares de 1853 impuso la censura previa. Esto es, en 1824 se inauguró una etapa signada por el cambio radical del marco de referencia en cuanto al diseño de la comunidad política y sus principios, que habría de consolidarse en el transcurso del siglo. El Estado mexicano adoptó la mayoría de las libertades modernas, entre ellas la de imprenta, en términos políticos; sin embargo, no rompió el vínculo con la religión católica, que se mantuvo como la religión nacional. Así, en el nuevo régimen, y durante casi toda la primera mitad de la centuria, la práctica de la censura estuvo ligada a un sistema de gobierno que reconocía como uno de sus principios constitucionales la religión católica y, por tanto, la protegía. En este régimen de unicidad religiosa, la censura previa, entendida como una práctica administrativa del Estado, se prohibió para las ideas y escritos de carácter político, pero se mantuvo para lo relativo a las de carácter religioso. ${ }^{25}$

25 En el Reglamento Provisional Político del Imperio Mexicano, de 1822, en los artículos 17 y 18, quedó expresamente consignada la prohibición en "materias de religión y disciplina eclesiástica”. Sería hasta junio de 1856 cuando “el proyecto de reformas deja por fin libre a la prensa para hablar sobre materias 
En lo que toca a la existencia de censura posterior, aun cuando no se expresara explícitamente, es evidente que, en tanto no estaba prohibida, estaba permitida. En efecto, la censura posterior se aplicó cuando un escrito violentaba o contravenía las disposiciones que regulaban la libertad de imprenta; se censuraba entonces con base en la prohibición, en la norma, cuando se incumplían algunas de las restricciones establecidas en la legislación. Pero entonces la censura no se ejercía de manera directa por los representantes del Poder Ejecutivo -como se ha acusado reiteradamente, y la mayoría de las veces sin fundamento, a lo largo de estos dos siglos- sino que requería, generalmente, la intervención del Poder Judicial y la consecución del debido proceso, salvo en los momentos en que privaba en el país una situación de excepción que permitía al Ejecutivo actuar en tal sentido. Esto es, para que un escrito fuera "censurado" se requería de una previa denuncia, presentada por autoridades, funcionarios -como era el caso de los fiscales o ministerios públicos, según la época-, corporaciones o individuos, paso obligado sin el cual, en tiempos de normalidad, no era posible actuar contra un escrito. Las autoridades del Poder Ejecutivo sólo han podido proceder de manera directa frente a la prensa en coyunturas bien definidas en las cuales, debido a situaciones de riesgo o alteración del orden en el país, el Poder Legislativo le ha concedido el uso de facultades extraordinarias y ha suspendido las garantías respectivas a los artículos $6^{\circ}$ y $7^{\circ}$ constitucionales, como lo muestran las colaboraciones de Coudart y Gantús. En todo caso, la censura posterior constituye la excepción y no la regla en el ejercicio de los derechos de expresión y publicación.

religiosas [...] El respeto al dogma católico como uno de los límites a la libertad de imprenta, que había permanecido en todas las constituciones mexicanas, incluida la de Cádiz”. Elba Chávez Lomelí, Lo público y lo privado en los impresos decimonónicos. Libertad de imprenta (1810-1882), México, Miguel Ángel Porrúa, 2009, p. 264. 
Ahora bien, es posible constatar que la censura posterior se ejerció en el México decimonónico de varias maneras -aunque, cabe señalar, tal concepto no se usaba en el lenguaje oficial, ni legal ni judicial-; esto es, se ejercía mediante la aplicación de medidas provenientes de alguno de los poderes o mediante la implementación de recursos legales y jurídicos, pero es necesario precisar cuáles fueron. Podemos identificar dos estrategias desarrolladas por las autoridades para "censurar" y evitar la circulación de algunos escritos. Por supuesto, para que esas formas de censura, que ahora precisaremos, fueran posibles, la base imprescindible era la existencia misma de una regulación de las libertades de expresión y de imprenta, que imponía ciertos límites. Esa regulación era dictada por el Poder Legislativo salvo, como ya hemos apuntado antes, en los casos de estado de excepción, durante los cuales el Poder Ejecutivo estaba facultado para ello. Con base en esa legislación, la primera forma de ejercer la censura la encontramos en el uso de facultades extraordinarias y suspensión de garantías. La segunda, que es, sin duda, la más interesante y que evidencia la habilidad desarrollada por las autoridades así como el estrecho contubernio entre poderes, es el procedimiento judicial. ${ }^{26}$

Existe también otra forma de poner freno a la libertad de imprenta que, justo en ese uso retórico del concepto, se ha asociado a "censura", pero que en los hechos no es tal, ni puede ser definida como tal, y es la represión extralegal y en algunos casos francamente violenta. ${ }^{27} \mathrm{Al}$ tratar sobre la prensa se suele usar el término censura como sinónimo de prohibición y represión, sin reparar en que son acciones diferentes. La confusión en el uso del término censura para todo acto de prohibición, restricción o represión de la imprenta, viene de la aplicación misma

${ }^{26}$ Gantús, Caricatura, pp. 263-383; y los artículos de Coudart y Gantús incluidos en este número.

27 Sobre el tema véase GanTús, Caricatura, pp. 271-278. 
que le daban autores en su época, quienes también asociaban la censura con la crítica. La existencia de la normativa y las estrategias de contención, así como la violencia, provocan una forma más de inhibición de la imprenta: la autocensura. Cabe precisar que en los trabajos reunidos en este dossier nos ocupamos de la censura política, principalmente. Por censura política entendemos aquella que ejercen las autoridades gubernamentales para tratar de controlar la circulación de ciertas opiniones o información sobre sus decisiones, desempeño y actuación en general. Censura y autocensura ponen en evidencia las preocupaciones -y contradicciones- que atraviesan a la sociedad política y dejan al descubierto lo que en cada proyecto de gobierno se juega; expresan también las alianzas y confrontaciones entre los medios impresos -y de comunicación- y los otros actores de la esfera pública.

Lo que sí podemos constatar es el uso reiterado del procedimiento judicial, que llevó en más de una ocasión a suspender o retirar de circulación un impreso y al encarcelamiento del escritor, editor o impresor -en algunas ocasiones incluido parte del personal de las imprentas o periódicos-. Esto es, no se procedía legalmente contra un periódico por disposición del Ejecutivo -aunque podía ser el promotor de la denuncia-, sino por causa expresa instrumentada por el Poder Judicial. Proceder en términos judiciales fue una estrategia que se fue afianzando con el correr del siglo, y se consolidó después de la reforma del artículo séptimo ocurrida en 1883, pero estuvo presente también durante la primera mitad, como lo muestra Víctor Villavicencio en su colaboración centrada en el año 1840. En todo caso podríamos hablar, pues, de censura judicial. Los diversos representantes del Poder Ejecutivo, por su parte, y como lo muestran los estudios aquí reunidos, tuvieron que recurrir a otras estrategias para limitar, frenar y prohibir -censurar-a los impresos, en particular a la folletería, en la primera mitad del siglo, y a los periódicos, en la segunda; en particular se valieron del uso de facultades 
extraordinarias, otorgadas por el Poder Legislativo. Los tres poderes, parece obvio, se preocuparon siempre por los alcances e impacto de la letra escrita y su circulación, por ello actuaron, fuera de manera independiente o, la mayoría de las veces, coludidos contra los impresos.

$$
* * *
$$

Las investigaciones que tienen como fuente principal a la prensa son incontables, menos son las que se ocupan de ella como objeto de estudio; buena parte de esos últimos están cruzados o tienen en su base la legislación de imprenta, referente imprescindible para situar y comprender muchos de los problemas relacionados con el universo de la prensa, los impresos y la imprentas, pero casi ninguno se adentra en el tema. En los estudios que ocupan la legislación como marco de referencia o en los que entran de lleno en la materia, o aquellos que se centran en la discusión sobre las libertades de expresión y de imprenta, suele privar una gran confusión sobre las leyes y demás disposiciones oficiales que estaban vigentes en cada momento dado. No pretendemos hacer un recuento historiográfico ni presentar un estado de la cuestión, pero es importante señalar que, salvo excepciones, no encontramos libros centrados en la legislación en la etapa decimonónica. ${ }^{28}$ Hay varios estudios que atienden al asunto de la libertad de prensa pero, o no constituye su interés principal o, sobre todo, no se adentran en el tema en términos de su legislación. Cabe apuntar que la mayoría de las publicaciones que se enfocan en la regulación o normativa de la libertad de imprenta se encuentran dispersas en revistas y libros.

La gran cantidad de disposiciones sobre libertad de imprenta, que abarcan desde circulares hasta leyes, emitidas por autoridades de los poderes Ejecutivo y Legislativo, y aun Judicial, -tanto

${ }_{28}$ Una de esas excepciones es el trabajo de CHávez Lomelí, Lo público. 
en tiempo de normalidad como en periodos excepcionales, en los que privaron suspensión de garantías y facultades extraordinarias-, aunadas a proclamas, planes y manifiestos de sublevados y pronunciados, que muchas veces afectaron la vigencia y acción de una disposición, reglamento o ley porque lo modificaron, suspendieron -temporal o definitivamente-, y que a veces se superponen unas a otras, hacen muy difícil saber con exactitud el marco normativo federal vigente en cada etapa, y eso se ve reflejado en la mayoría de los estudios en la materia publicados hasta ahora.

Entre los esfuerzos que desde la historia se han hecho en esos terrenos para tratar de dilucidar y profundizar en la comprensión de la legislación de prensa, su papel e importancia, se encuentra el libro de Elba Chávez Lomelí, Lo público y lo privado en los impresos decimonónicos. Libertad de imprenta (18101882), que procura seguir la evolución de la prensa atendiendo a la reglamentación, esto es, a las formas que se implementaron para regularla bajo los diferentes regímenes gubernamentales de su periodo de estudio, así como a las estrategias empleadas para controlarla y reprimirla. ${ }^{29}$ Destaca el minucioso trabajo " $\mathrm{La}$ regulación de la libertad de prensa (1863-1867)” de Laurence Coudart, que centra su interés en una etapa muy descuidada por la historiografía de la prensa, que es la del segundo imperio. ${ }^{30}$ Por su parte, en su libro Caricatura y poder político, Fausta Gantús dedica un par de capítulos a comprender el proceso de regulación por medio de la aplicación y modificación del artículo séptimo constitucional, el uso de facultades extraordinarias y la estrategia judicial, entre 1867 y $1888 .{ }^{31}$ Desde el derecho, el trabajo más abarcador sobre el tema de la libertad de prensa y su regulación, es el elaborado en coautoría por Fernando Gómez

29 Chávez Lomelí, Lo público.

30 Laurence Coudart, "La regulación de la libertad de imprenta (18631867)”, en Historia Mexicana, LXv: 2 (258) (oct.-dic. 2015), pp. 629-687.

31 Gantús, Caricatura. 
de Lara, Manuel González Oropeza, David Vega Vera y Javier Zenteno Barrios, Estudios sobre la libertad de prensa en Méxi$c o$, en el que hacen un recorrido por la centuria decimonónica iniciando con Cádiz en 1812 y cerrando con la Constitución de 1917, deteniéndose tanto en leyes como en discursos y en argumentaciones jurídicas. ${ }^{32}$

Ante este escenario y las continuas dudas que surgen al elaborar o revisar trabajos sobre la prensa respecto a la fiabilidad de los datos asentados, un pequeño grupo de investigadores interesados en el tema nos propusimos la tarea conjunta de tratar de avanzar un poco en la materia. Dos de los trabajos de este dossier centran su atención en momentos y situaciones concretas, atendiendo a debates -en la esfera pública y en los espacios políticosy conflictos suscitados entre diversos actores, promulgación de disposiciones y leyes, y su aplicación.

El periodo de 1810-1813, que constituye un momento de transición en el que conviven el régimen colonial con el nacimiento de la nación mexicana, es objeto de análisis de Abraham Chimal. El autor se da a la tarea de estudiar las estrategias desplegadas por los realistas para frenar la difusión por medio de la prensa de las ideas insurgentes valiéndose para ello, por un lado, de la restricción de la libertad de imprenta y, por el otro, de la confrontación mediante la réplica, esto es, valiéndose ellos mismos del uso de los impresos. En este contexto, se analizan la legislación en la materia y los discursos elaborados por ambos bandos. En su estudio identifica también el surgimiento de un nuevo tipo de prensa que resultaba a la vez política, periódica y crítica.

Un par de décadas después, en 1840, signado por el cruce de intereses políticos en la búsqueda por definir el mejor régimen para un país que se debatía entre el federalismo y el centralismo y en el que reaparecía la consideración del monarquismo

32 Gómez de Lara, Estudios. 
como una posibilidad para solucionar la conflictiva situación nacional, se centra el estudio de Víctor Villavicencio. ${ }^{33}$ Su interés está puesto en analizar el ambiente y el debate político en torno de la libertad de imprenta y la aplicación de las leyes en la materia con motivo de una publicación a favor del monarquismo que resultó polémica y controversial y provocó la respuesta tanto de la propia prensa, en lo discursivo, y de las autoridades, en lo legal, sobre el ejercicio y los límites de esa libertad y la forma en que afectaban al sistema de gobierno, y su existencia misma.

Los otros dos artículos, aunque distintos en el manejo de sus temas y perspectivas, de alguna manera se complementan entre sí pues reconstruyen los marcos normativos vigentes a lo largo del siglo, de 1821 a 1883, incluyendo en cada caso anexos con el detalle de la legislación sobre la materia, los cuales permiten claridad sobre el punto. Así, Laurence Coudart, a partir del análisis de las leyes y de las Memorias ministeriales emitidas entre 1821 y 1867, reflexiona sobre los sentidos y usos de la libertad de imprenta, así como sobre los efectos y alcances de regulación, poniendo especial atención al papel que juega la censura y cómo todo esto se relaciona con la "edificación del joven Estado" mexicano, la conformación de la sociedad política y la ampliación de la esfera pública. Su estudio revela las tensiones entre los distintos poderes -Ejecutivo, Legislativo y Judicial- que conducen a prácticas autoritarias que se quieren centralizadoras, mediante del recurso de facultades extraordinarias otorgadas al Poder Ejecutivo para imponer normas legales. De igual modo expone la permanente iniciativa de los gobiernos, sin importar la corriente política en el poder, en búsqueda de una suerte de “institucionalización” de la prensa periódica, pero en realidad

${ }^{33}$ Un estudio del mismo caso que analiza Villavicencio, pero centrado en el papel del impresor, es el de José Miguel Chávez Sánchez, "La polémica que nunca fue: Ignacio Cumplido y los medios impresos durante la primera mitad del siglo XIX", tesis de licenciatura en historia, México, Universidad Nacional Autónoma de México, 2017. 
rebasados por el ineluctable desarrollo mediático y sus propias contradicciones. En su conjunto este trabajo deja en evidencia el carácter experimental del periodo.

Fausta Gantús, por su parte, valiéndose de la caricatura política como espacio de provocación, analiza las representaciones que sobre la libertad de imprenta y de expresión se elaboraron desde el espacio de la sátira visual para reflexionar en torno a la legislación vigente entre 1868 y 1883. En igual sentido, reconstruye el escenario periodístico imperante y se adentra en precisar los marcos normativos vigentes, recurriendo para ello a las leyes, reglamentos, reformas constitucionales y disposiciones oficiales. En su estudio, expone las particularidades de un periodo de preocupación por el afianzamiento del Estado y de búsqueda de mecanismos de control sobre la prensa, marcado por el uso de facultades extraordinarias y suspensión de garantías y la pretensión de modificar el artículo séptimo constitucional.

Las colaboraciones aquí reunidas son resultado del esfuerzo conjunto. Los autores trabajamos de manera sistemática por más de dos años investigando y escribiendo nuestras colaboraciones, al tiempo que analizando y reflexionando de manera colectiva sobre el tema central del mismo. ${ }^{34}$ Es ese esfuerzo el que nos permite publicar hoy este dossier con el que esperamos

${ }^{34}$ Inició este proyecto con la presentación de propuestas y primeros bosquejos en la mesa "Libertades de expresión y de imprenta", realizada en el marco del X Encuentro Internacional de Historiadores de la Prensa, celebrado en Valencia, España, en octubre de 2016 -en ella participaron, además de quienes conforman este dossier: Joëlle Chassin, Frédéric Johansson, Alicia Salmerón, Matilde Souto y Regina Tapia. Para que la mesa fuera posible, los integrantes de la misma fueron convocados desde febrero de ese mismo año a pensar en el tema y definir sus propuestas. Posteriormente, a lo largo de 2017, nos reunimos en dos seminarios-taller, realizados en junio y septiembre, y discutimos también nuestros textos en varias sesiones del Seminario de Historia Política, entre finales de 2017 y principios de 2018. En el segundo seminario taller y en la sesión extraordinaria del Seminario de Historia Política, contamos con la valiosa colaboración de colegas que aceptaron la tarea de comentar los textos: Edwin Alcántara, Arturo Ríos, Catherine Andrews y Matilde Souto. 
contribuir de manera importante a esclarecer el derrotero y las vicisitudes de la historia de la libertad de imprenta y sus leyes en el México decimonónico y de las tensiones políticas provocadas por la polarización entre la defensa de esa libertad y la necesidad de su regulación justificada en la preservación del orden. Se trata de una historia que avanza en un terreno poco trabajado, poniendo atención a las maneras en que se otorga y restringe la libertad de imprenta y que se constituye imprescindible para entender los marcos legislativos que la posibilitaron o impidieron a lo largo del siglo xix.

Fausta Gantús Instituto de Investigaciones Dr. José María Luis Mora 